\title{
WIBRAGEC

\section{O IMPACTO NO DESCONTO DE LICITAÇÃO COM A ADOÇÃO DE MENOR PREÇO OU MAIOR DESCONTO EM OBRAS E SERVIÇOS DE ENGENHARIA ${ }^{1}$}

\author{
FERNANDEZ, Maria Luiza Soares; MUTTI, Cristine do Nascimento (2); \\ (1) Universidade Federal de Santa Catarina, m.l.fernandez@ posgrad.ufsc.br (2) Universidade \\ Federal de Santa Catarina, cristine.mutti@ufsc.br
}

\begin{abstract}
RESUMO
Através deste estudo analisou-se se há significância estatística entre desconto proveniente do critério de julgamento por menor preço ou por maior desconto nas amostras coletadas de licitações realizadas com amparo do Regime Diferenciado de Contratações. Há autores que defendem adoção de maior desconto ao invés de menor preço para obras e serviços de engenharia para evitar o jogo de planilha e o jogo de cronograma. Como método de pesquisa, coletou-se dados do Departamento Nacional de Infraestrutura de Transportes de 2017 a 2020, sendo 40 licitações com critério de julgamento menor preço e outras 40 licitações com critério de julgamento maior desconto. Através do teste de Shapiro Walk, observou-se que o teste é significativo ( $p<0,05)$, de forma que os dados tanto de menor preço quanto de maior desconto diferem significativamente de uma distribuição normal. Assim, optou-se por utilizar o teste nãoparamétrico de Mann-Whitney. O teste mostrou que a escolha do critério de julgamento (maior desconto ou menor preço) não tem efeito sobre o valor do desconto $(U=640, p>0,05, r=-0,17)$. A maior contribuição do trabalho é sobre a necessidade de ampliar a discussão sobre a adoção de maior desconto como preferência em licitações de obras e serviços de engenharia regidas pelo RDC.
\end{abstract}

Palavras-chave: Obras Públicas, Regime Diferenciado de Contratações, Licitações, Desconto.

\begin{abstract}
This study analyzed whether there is statistical significance between discount from the criterion of judgment for the lowest price or for the highest discount in the samples collected from bids carried out under the Differentiated Contracting Regime. Some authors advocate adopting a higher discount instead of a lower price for engineering works and services to avoid the spreadsheet game and the schedule game. In this research, data from the period of 2017 to 2020, were collected from the National Department of Transport Infrastructure, with 40 bids with the lowest price judgment criterion and 40 other bids with the highest discount judgment criterion. Through the Shapiro Walk test, it was observed that the test is significant ( $p$ $<0.05)$, so that the data with the lowest price and the highest discount differ significantly from a normal distribution. Thus, the Mann-Whitney non-parametric test was chosen for the study. The test showed that the choice of the judgment criterion (higher discount or lower price) has no effect on the discount amount $(U=640, p>0.05, r=-0.17)$. The greatest contribution of this work is to highlight the need to broaden the discussion on the adoption of a greater discount as a preference in tenders for works and engineering services governed by the DRC.
\end{abstract}

Keywords: Public Projects, Differentiated Contracting Regime, Bidding process, Price Reduction.

\section{INTRODUÇÃO}

Segundo Decisão TCU n ${ }^{\circ}$ 1.090/2007-Plenário (TCU, 2007), o jogo de planilha pode ser definido como itens superfaturados que, no decorrer da execução da obra, podem ter os

\footnotetext{
1 FERNANDEZ, M. L. S.; MUTTI, C. do N. O impacto no desconto de licitação com a adoção de menor preço ou maior desconto em obras e serviços de engenharia. In: SIMPÓSIO BRASILEIRO DE GESTÃO E ECONOMIA DA CONSTRUÇÃO, 12., 2021, Maceió. Anais[...] Porto Alegre: ANTAC, 2021. p.1-8. Disponível em: https://eventos.antac.org.br/index.php/sibragec/article/view/454. Acesso em: 2 out. 2021.
} 
seus quantitativos aumentados mediante aditivos contratuais. Tais itens superfaturados existem, mesmo em casos que o preço global da obra seja compatível com o de mercado.

Baeta (2012) afirma que o jogo de planilha é confirmado em virtude de diversas circunstâncias e causas diferentes, mas, especialmente pelos elementos descritos no Quadro 1.

Quadro 1 - Fatores que indicam jogo de planilha

\begin{tabular}{|l|}
\hline Fatores \\
\hline Acréscimo de quantidades de itens originais com sobrepreços \\
\hline $\begin{array}{l}\text { Decréscimo ou supressão de quantidade de itens originais com subpreços } \\
\text { Alteração dos preços originais por meio de termos aditivos (reequilíbrio econômico-financeiro) }\end{array}$ \\
\hline $\begin{array}{l}\text { Inclusão de itens novos com sobrepreços ou com descontos inferiores ao ponto de equilíbrio } \\
\text { econômico-financeiro do contrato }\end{array}$ \\
\hline $\begin{array}{l}\text { Paralisação ou abandono da obra pela contratada, após a execução dos serviços com os preços mais } \\
\text { vantajosos ao contratado. }\end{array}$ \\
\hline
\end{tabular}

Fonte: Baeta (2012)

Borges (2000) reitera que o favorecimento do menor preço, como praticamente único critério de julgamento das propostas das licitações, vem causando consequências nocivas. Os contratados ingressam nas licitações oferecendo preços irreais, subfaturados para vencer o certame de qualquer maneira. Ainda, segundo o autor, efetuam serviços malfeitos e empregam material de qualidade inferior. Também recorrem à "indústria dos aditivos" para conquistar um preço que lhes permita algum lucro. Ou, abandonam o contrato no meio da execução por simplesmente não haver mais recursos financeiros para seu pagamento.

Segundo Baeta (2016), o julgamento pelo maior desconto evita o jogo de planilha e o jogo de cronograma. Também proporciona celeridade ao processamento da licitação, pois tornam rápidas as análises de exequibilidade e economicidade. $\mathrm{O}$ autor recomenda, sempre que possível, que as obras e serviços de engenharia sejam licitados com critério de julgamento pelo maior desconto.

Assim, o presente trabalho pretende contribuir com uma análise estatística comparando licitações que adotam o Regime Diferenciado de Contratações, abrangendo 40 licitações de com critério de julgamento menor preço e 40 licitações com critério de julgamento maior desconto provenientes do Departamento Nacional de Infraestrutura de Transportes, para concluir se há diferença estatisticamente significativa entre o desconto concedido em cada um dos critérios de julgamento.

Essa pesquisa limitou-se a obras e serviços de engenharia que adotaram o Regime Diferenciado de Contratações, regido pela Lei ${ }^{\circ}$ 12.462/11 (BRASIL, 2011).

É necessário ressaltar que os critérios de julgamento maior desconto e menor preço permanecem na Lei $\mathrm{n}^{\circ} 14.133 / 21$ que foi aprovada em 01 de abril de 2021 como a nova lei de licitações e contratos administrativos (BRASIL, 2021), de forma que a discussão mantem-se válida.

\section{REVISÃO BIBLIOGRÁFICA}

Entre as diferenças entre a Lei $n^{\circ} 8.666 / 93$ (BRASIL, 1993) e a Lei $n^{\circ} 12.462 / 11$ (BRASIL, 2011), a mais relevantes para esse estudo são descritas no Quadro 1.

Quadro 1- Diferenças entre 8.666/93 (BRASIL, 1993) e 12.462/11(BRASIL, 2011) relevantes para essa pesquisa

\begin{tabular}{|c|c|c|}
\hline Tópicos & Lei 8.666/93 & RDC(Lei 12.462/11 e Decreto 7.581/11) \\
\hline $\begin{array}{l}\text { Tipos de licitação e } \\
\text { critérios de julgamento }\end{array}$ & $\begin{array}{l}\text { Menor Preço; } \\
\text { Melhor Técnica; }\end{array}$ & $\begin{array}{l}\text { Menor Preço ou Maior Desconto; } \\
\text { Melhor combinação de técnica e preço; }\end{array}$ \\
\hline
\end{tabular}




\begin{tabular}{|l|l|l|}
\hline & $\begin{array}{l}\text { Técnica e Preço; } \\
\text { Maior Lance ou Oferta; }\end{array}$ & $\begin{array}{l}\text { Melhor técnica ou conteúdo artístico; } \\
\text { Maior oferta de preço; } \\
\text { Maior retorno econômico }\end{array}$ \\
\hline $\begin{array}{l}\text { Julgamento da proposta } \\
\text { de preços }\end{array}$ & Ocorre pelo menor preço; & $\begin{array}{l}\text { O julgamento pelo menor preço ou maior } \\
\text { desconto levará em conta o menor gasto para } \\
\text { a Administração Pública, considerando os } \\
\text { parâmetros mínimos de qualidade definidos } \\
\text { no instrumento convocatório. }\end{array}$ \\
\hline
\end{tabular}

Fonte: Baeta (2016)

Assim como o tipo "menor preço" da Lei n 8.666/93 constitui-se na licitação realizada com maior frequência com fundamento naquela Lei, o critério menor preço ou maior desconto é a regra das licitações realizadas com apoio do RDC (BAETA, 2016).

Nester (2012) afirma que, para o menor preço, atendidos os parâmetros mínimos de qualidade determinados pelo edital, será declarada vencedora a proposta que ofertar menor valor (desde que não seja inexequível). Para o cálculo da proposta mais vantajosa para a Administração, poderão ser considerados custos indiretos, relacionados com as despesas de manutenção, utilização, reposição, depreciação e impacto ambiental, conforme estabelecido no artigo 26 do Decreto 7.581/2011 (BRASIL, 2011)

Já o "maior desconto" tem utilidade nos casos em que a Administração possuir informações plausíveis sobre o custo da obra ou serviço, de forma que ele tenha sido fixado com precisão no edital. $\mathrm{O}$ desconto ofertado pelo vencedor deverá permanecer durante toda a contratação, inclusive para possíveis aditamentos (NESTER, 2012).

Assim, quando o critério de maior desconto for aplicado em obras e serviços de engenharia, segundo o artigo 19 do Decreto 7.581/2011 (BRASIL, 2011), o percentual de desconto deverá incidir linearmente sobre o preço de todos os itens do orçamento estimado no instrumento convocatório". Dessa forma se evita a possibilidade de jogo de planilha devido ao fato do desconto ser aplicado em bloco (NESTER, 2012).

\section{MÉTODO}

Os dados foram obtidos através de buscas nos editais de licitações do Departamento Nacional de Infraestrutura e Transporte. O filtro aplicado foi para Regime Diferenciado de Contratações - RDC. Após a compilação dos dados utilizando planilhas, o filtro aplicado foi Critério de Julgamento, selecionando-se "Menor Preço", "Maior Desconto". A partir disso, chegou-se a 40 obras e/ou serviços de engenharia com critério de julgamento do tipo "menor preço" e a 40 obras e/ou serviços de engenharia com critério de julgamento do tipo "maior desconto".

O foco da pesquisa é ampliar as discussões em torno de uso de "maior desconto" como preferência em licitações com amparo no RDC, em detrimento do "menor preço". Para isso, analisou-se se há diferença estatisticamente significativa entre os descontos provenientes de licitações com critério de julgamento "maior desconto" para "menor preço".

Assim, como o foco foi comparar os descontos (valores numéricos) entre dois grupos independentes, o método utilizado foi conforme a Figura 1. 


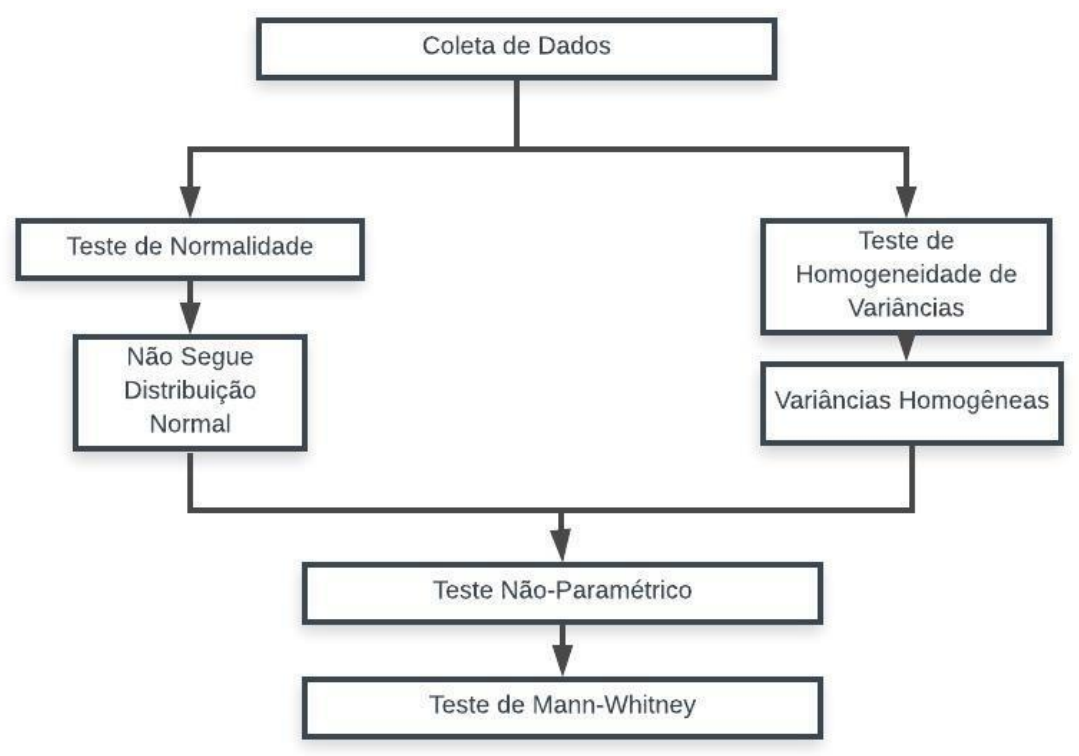

Fonte: Autoras (2021)

Para análise da normalidade, aplicou-se o teste de Shapiro-Wilk (LEOTTI; COSTER; RIBOLDI, 2012). Para o teste de Shapiro-Wilk, a hipótese nula considerou a distribuição de dados normais para um $\mathrm{p}>0,05$ e a hipótese alternativa que a distribuição de dados não é normal para um $\mathrm{p} \leq 0,05$.

Já para a análise da homogeneidade de variância, aplicou-se o teste de Levene (LEVENE, 1960). Para o teste de Levene, a hipótese nula considerou a variância dos grupos são homogêneas para um $p>0,05$ e a hipótese alternativa que a variância dos grupos não são homogêneas para um $\mathrm{p} \leq 0,05$.

Tanto para normalidade quanto para homogeneidade de variância adotou-se o valor $\mathrm{p}$ como menor ou igual ao nível de significância de 0,05 para que a hipótese nula seja falsa. Se o valor de p for inferior a 0,05 , a diferença é considerada estatisticamente significativa. (LARSON; FARBER, 2015)

Como a normalidade foi violada, prosseguiu-se ao uso de teste não-paramétrico (SPRENT; SMEETON, 2007). Para tal propósito, por se tratar de duas amostras independentes (maior desconto e menor preço), empregou-se o teste de Mann-Whitney (MANN; WHITNEY, 1947) No Mann-Whitney as hipóteses tratam da mediana entre grupos.

Assim, as hipóteses definidas foram:

H0: Md maior desconto $=$ Md menor preço

onde,

Md =mediana;

H0 = hipótese nula;

H1: Md maior desconto $\neq$ Md menor preço

onde, $\quad$ Md =mediana;

H1 = hipótese alternativa; 


\section{RESULTADOS E DISCUSSÕES}

Com os dados compilados em tabelas no software Microsoft Excel, procedeu-se a análise da estatística descritiva dos dados. Na estatística descritiva, chegou-se ao exposto no Quadro 2.

Quadro 2 - Estatística descritiva dos dados

\begin{tabular}{|l|l|l|l|l|}
\hline & Maior Desconto & \multicolumn{2}{l|}{ Menor Preço } \\
\hline & Estatística & Erro Padrão & Estatística & Erro Padrão \\
\hline Média de Desconto Licitação & $31,003704 \%$ & 3,55 & $38,690893 \%$ & 3,65 \\
\hline 95\% Intervalo de Confiança & 23,812718 & & 31,301367 & \\
Para Média & 38,194690 & & 46,0800418 & \\
\hline Mediana & 29,276094 & 0 & 48,728284 & \\
\hline Variância & 505,566 & & 533,868 & \\
\hline Desvio Padrão & 22,4847941 & & 23,1055878 & \\
\hline
\end{tabular}

Fonte: Autoras (2021)

A partir disso, procedeu-se a análise de normalidade das amostras utilizando o teste de Shapiro-Wilk. O teste Shapiro Wilk de normalidade utiliza valores amostrais ordenados elevados ao quadrado e tem sido o mais empregado por ser o mais aceito que diversos testes alternativos (LEOTTI; COSTER; RIBOLDI, 2012). Com isso, obteve-se os resultados expostos no Quadro 3.

Quadro 3 - Resultado no teste de Shapiro Wilk

\begin{tabular}{|l|l|l|l|}
\hline Maior Desconto ou Menor Preço? & \multicolumn{3}{|l|}{ Shapiro Wilk } \\
\hline & Estatística & df & Sig. \\
\hline Menor Preço & 0,931 & 40 & 0,017 \\
\hline Maior Desconto & 0,888 & 40 & 0,001 \\
\hline
\end{tabular}

Fonte: Autoras (2021)

Pode-se relatar que, para os descontos para critério de julgamento Menor Preço $\mathrm{D}(40)=0,931, \mathrm{p}<0,05$ e para os descontos de critério de julgamento Maior Desconto $\mathrm{D}(40)=0,888, \mathrm{p}<0,05$, de modo que conclui-se que foram ambos significativamente nãonormais.

Seguindo o fluxograma indicado no método, iniciou-se o teste de homogeneidade de variâncias. Para isso, optou-se nessa pesquisa pelo teste de Levene (LEVENE, 1960). Os resultados estão indicados no Quadro 4.

Quadro 4 - Resultado no teste de Levene

\begin{tabular}{|l|l|l|l|}
\hline & Teste de Levene de Homogeneidade de Variâncias & Sig. \\
\hline & & F & 0,681 \\
\hline Desconto & Supondo variâncias homogêneas & 0,170 & \\
\hline & Supondo variâncias não homogêneas & & \\
\hline
\end{tabular}

Fonte: Autoras (2021)

O teste de Levene testa se as variâncias nos dois grupos são iguais (isto é, se a diferença entre as variâncias é zero). Desse modo, se o teste de Levene for não-significativo (nesse caso, $\mathrm{p}>0,05$ ), é necessário aceitar a hipótese nula de que a diferença entre as variâncias é zero. Para os dados desta pesquisa, o teste de Levene não é significativo (pois $\mathrm{p}=0,681$, o qual é maior que 0,05 ).

A hipótese de homogeneidade de dados não foi violada porém os dados não são normalmente distribuídos. Por isso, a solução foi utilizar um teste não-paramétrico. $\mathrm{O}$ teste não-paramétrico utilizado foi o de Mann-Whitney (MANN;WHITNEY, 1947). O resultado foi expresso no Quadro 5. 
Quadro 5 - Resultado do teste de Mann-Whitney

\begin{tabular}{|l|l|l|l|}
\hline & \multicolumn{4}{|l|}{ Resultado Mann-Whitney } \\
\hline & $\mathrm{N}$ & Média dos Postos & Soma dos Postos. \\
\hline Maior Desconto & 40 & 36,50 & 1460,00 \\
\hline Menor Preço & 40 & 44,50 & 1780,00 \\
\hline
\end{tabular}

Fonte: Autoras (2021)

Com a análise das estatísticas testes, obteve-se o exposto no Quadro 6.

Quadro 6 - Resultado do teste de Mann-Whitney

\begin{tabular}{|l|l|}
\hline & Desconto \\
\hline Mann-Whitney U & 640,00 \\
\hline (Sig. Assint. Bilateral) & 0,124 \\
\hline Z & $-1,540$ \\
\hline
\end{tabular}

Fonte: Autoras (2021)

O teste de Mann-Whitney mostrou que o critério de julgamento (ser menor preço ou maior desconto) não tem efeito sobre os descontos $(U=640 ; p>0,05)$. Assim, não há evidência para rejeitar a hipótese nula de que não há diferença entre o desconto de obras e serviços de engenharia com critério de julgamento menor preço e maior desconto (COHEN, 1998).

O tamanho do efeito foi calculado com uso de conforme a Equação 1 (ROSENTHAL, 1991):

$r=\frac{Z}{\sqrt{N}}$

onde, $\quad \mathrm{Z} \quad=$ escore- $\mathrm{Z}$;

$\mathrm{N} \quad=$ tamanho dos valores em estudo;

$r=\frac{-1,54}{\sqrt{80}}=-0,17$

Isso demonstra que o tamanho de efeito é pequeno. (COHEN, 1988)

Apesar da mediana de desconto por menor preço ser maior que a do maior desconto para as amostras analisadas (Figura 2), essa diferença entre os descontos pelo critério de julgamento "maior desconto" e "menor preço" não é considerada estatisticamente significativa. 


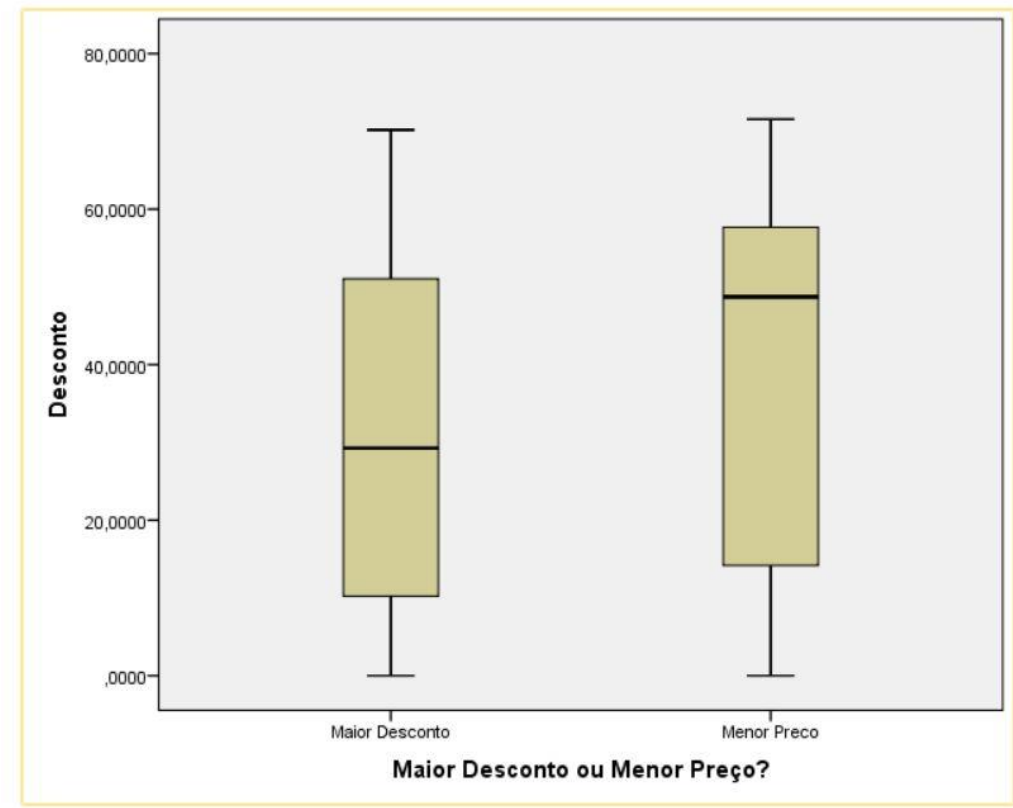

Fonte: Autoras (2021)

\section{CONSIDERAÇÕES FINAIS}

A contribuição do trabalho é levantar a discussão sobre o uso preferencial de maior desconto em obras e serviço de engenharia em detrimento de menor preço. A análise estatística dessa pesquisa mostrou que não há evidência para rejeitar a hipótese nula que seria que não há diferença entre o desconto de obras e serviços de engenharia que utilizam menor preço ou maior desconto como critério de julgamento.

Desse modo, de acordo com esse estudo, a escolha do critério de julgamento (menor preço ou maior desconto) não tem efeito sobre a magnitude do desconto na licitação.

Como foi relatado no decorrer da pesquisa, há autores (BAETA, 2016; NESTER, 2012) que afirmam que a aplicação do maior desconto evita o jogo de planilha - incluindo-se, assim, todos os prejuízos que essa prática acarreta para a Administração Pública e a sociedade. Considerando-se isso, abre-se a discussão sobre quais seriam os motivos para ainda haver licitações com aparo no RDC que utilizam menor preço como critério de julgamento em detrimento de maior desconto se não há um maior impacto na economia que seja estatisticamente significante para a Administração que justifique o menor preço em detrimento do maior desconto para obras e serviços de engenharia.

\section{REFERÊNCIAS}

BAETA, A. P. Regime Diferenciado de Contratações Públicas: aplicado às licitações e contratos de obras públicas. São Paulo: Pini, 2016.

BAETA, A. P. Orçamento e Controle de Preços de Obras Públicas. São Paulo: Pini, 2012.

BORGES, A. M. G. O equilíbrio econômico-financeiro nos contratos administrativos. Boletim de Licitações e Contratos, v.13, n.7, p.386-392, jul. 2000

BRASIL. Lei n.o 14.133, de 1 de abril de 2021. Institui a Lei de Licitações e Contratos Administrativos. Disponível em: < https://www.in.gov.br/en/web/dou/-/lei-n-14.133-de1-de-abril-de-2021-311876884>. Acesso em: 2 abril. 2021. 
BRASIL. Lei n.o 12.462, de 4 de agosto de 2011. Institui o Regime Diferenciado de Contratações -RDC e dá outras providências. Disponível em: http://www.planalto.gov.br/ccivil_03/_ato2011-2014/2011/Decreto/D7546.htm. Acesso em: 12 março. 2021.

BRASIL. Decreto noo 7.581, de 11 de outubro de 2011. Regulamenta o Regime Diferenciado de Contratações. Disponível em: http://www.servidor.gov.br/arq_editaveis/pdf/legislação/Lei\%208666Consolidada.pdf.

Acesso em: 12 março. 2021.

BRASIL. Tribunal de Contas da União. Acórdão 1.090/2007-Plenário. Brasília. Disponível em: http://www.tcu.gov.br/Consultas/Juris/Docs/judoc/Acord/20070611/TC008-219-2006-9.doc. Acesso em: 01 mar. 2021.

COHEN, J. Statistical power analysis for the behavioral sciences (2. ${ }^{a}$ ed.). Hillsdale: Lawrence Erlbaum Associates, 1988.

LARSON, R.; FABER B. Estatística Aplicada. Tradução José Fernando Pereira Gonçalves. $6^{\text {a }}$.ed. São Paulo: Pearson Education do Brasil, 2015

LEOTTI, V. B.; COSTER, R.; RIBOLDI, J. Normalidade de variáveis: métodos de verificação e comparação de alguns testes não-paramétricos por simulação. Revista HCPA. Porto Alegre. Vol. 32, no. 2 (2012), p. 227-234, 2012.

LEVENE, H. Robust tests for equality of variances. Contribution to Probability and Statistics. Stanford, CA: Stanford University Press, p.278-292, 1960.

MANN, H.B; WHITNEY, D.R. On a test $\mathrm{f}$ whether one of two random variables is stochastically larger than the other. Annals of Mathematical Statistics. v.18, p.50-60. 1947.

NESTER, A. W. Os critérios de julgamento previstos no Regime Diferenciado de Contratações Públicas. In: JUSTEN FILHO, Marçal; PEREIRA, Cesar A. Guimarães (Coord.). O Regime Diferenciado de contratações Públicas (RDC): comentários à Lei $\mathbf{n}^{0}$ 12.462 e ao Decreto no 7.581. Belo Horizonte: Fórum, 2012. p. 236.

SPRENT, P.; SMEETON, N.C. Applied non parametric statistical methods. Boca Raton: Chapman \& Hall, 2007. 530 p.

ROSENTAL, R. Meta-analytic procedures for social research (revise). Newbury Park (CA): Sage, 1991. 